\title{
Using the Product Impact Tool for Prospective Thinking
}

\author{
RAUB Thomas ${ }^{\mathrm{a}}$; DORRESTIJN Steven ${ }^{\mathrm{b}}$ and EGGINK Wouter ${ }^{\mathrm{a}}$ \\ a University of Twente, Enschede, Netherlands \\ ${ }^{b}$ Saxion University of Applied Sciences, Enschede, Netherlands \\ * Corresponding author e-mail: w.eggink@utwente.nl \\ doi: 10.21606/dma.2017.262
}

\begin{abstract}
The ever rising role of products and technologies in humans' lives is increasing the call for ways to understand and investigate their influences, in the form of prospective analytical methods. This paper proposes one such method, based upon the Product Impact Tool. This Tool was developed to combine both philosophy of technology and design for usability perspectives. Its effects offer potential for prospective and reflective purposes, and can be used to investigate and structure ideas about the impacts of both current and future technologies. The proposed method offers an addition to existing tools within the field of prospective analysis. This added value is demonstrated through a case study of a concept for future personal transport. Through this case study, it is shown that the proposed method can help uncover information that remained hidden by conventional approaches, by inducing a critical investigation of the subject from multiple perspectives. Such information will aid analysts and strategists in their work, leading to more effective, desirable, and responsible technologies being developed and implemented.
\end{abstract}

Product Impact Tool; prospective thinking; future planning; strategy development

\section{Introduction}

The role of technology has become ever more important in the daily lives of humans. The products that they use change who they are and what they do. This prominence brings with it a need for analytical methods to investigate and discuss the potential impact of future developments. Current methods for analysis and strategic development of new technologies mainly focus on economic and logistical aspects, like price and roadmapping. However, they often do not take into account aspects like societal impact and human-technology relations (Raub, 2017). This represents an opportunity for the development of investigation methods that do look at new technologies from this perspective. One means for such a method can be found in the Product Impact Tool (PIT) (Dorrestijn, 2012). This paper will propose and discuss an analytical method of using the PIT to study future innovations, in an effort to aid analysts and strategists in their work. 
In the first section, the PIT itself will be discussed. The focus will lie on both the prospective and reflective capabilities of the PIT's four quadrants. This section will also examine the potential for extending the PIT's scope beyond specific and material products, towards also more abstract concepts like (innovation) strategies.

The second section will present the proposed analytical method of using the PIT. Both this method and the PIT in itself are compared to existing strategic approaches, in order to discern its place within and relation to the field of prospective analysis.

The third section describes a case study, where the proposed method is applied to a concept for future personal transport by the Dutch Study Centre for Technology Trends (STT). The concept proposes a system wherein autonomous vehicles become a rentable service, that fulfils people's everyday needs for transportation. This system is analysed with the PIT, to investigate its impact on its users and on society as a whole. In doing so, it can be shown what added value both the PIT and the proposed method can bring to the field of prospective thinking.

\section{Product Impact Tool}

The PIT, as developed and refined by Dorrestijn (2012), consists of four 'quadrants', each containing three 'effects' (figure 1). The twelve effects together aim to represent the ways in which products and technologies impact the lives of individuals, as well as society as a whole. These effects originate from the fields of philosophy of technology and design for usability. The PIT is meant to induce reflection on the way technology influences humans. Descriptions of each of the effects can be found on the PIT's website (Dorrestijn, 2016). In the following, each of the PIT's quadrants and effects will be shortly discussed on their potential for reflective and prospective thinking. For the purposes of this paper, the most recent iteration as of writing will be used (Dorrestijn, 2017).

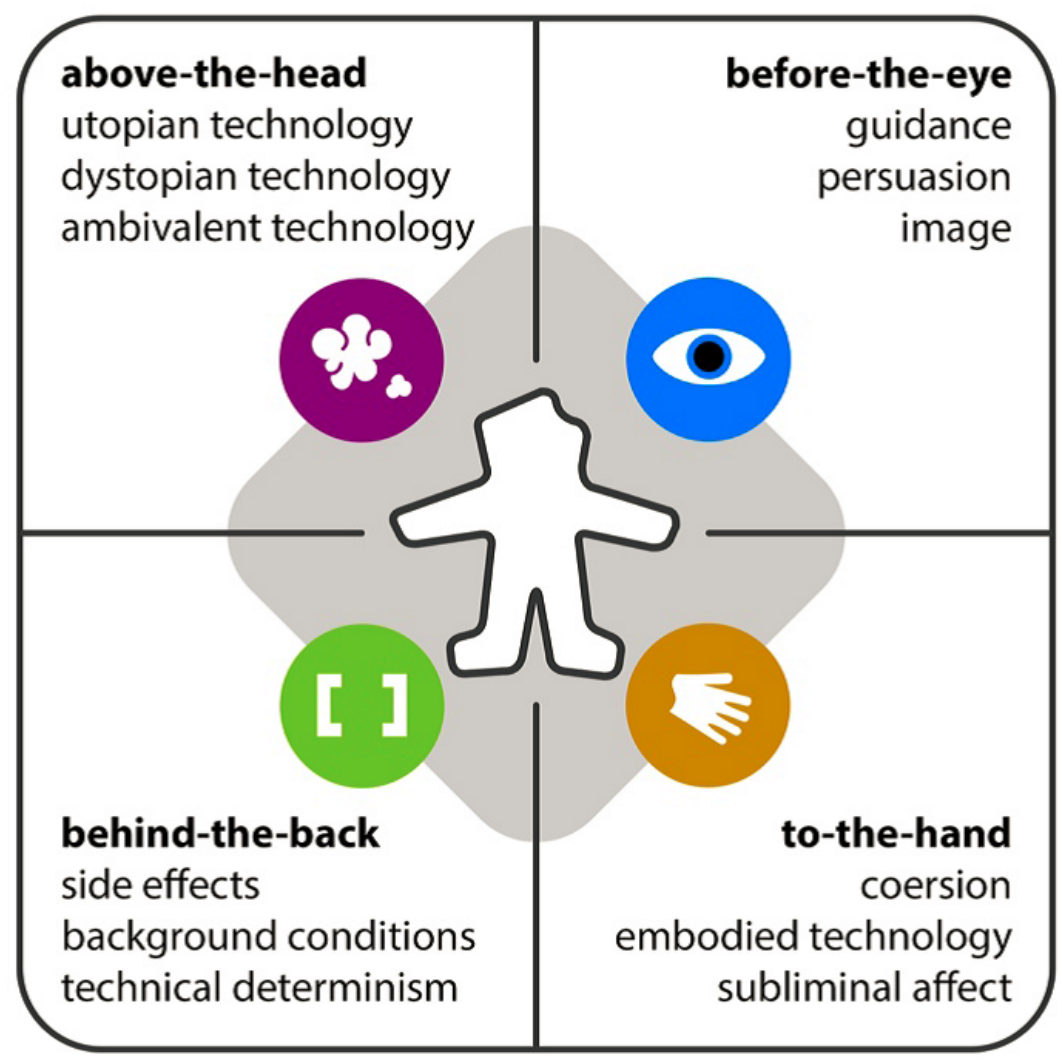




\subsection{Before the eye}

The before-the-eye quadrant details the ways in which technology influences the cognitive systems, often making use of humans' senses. Through this direction, products impact the decision-making process, by providing information and ideas to their user, while still offering them a free choice. This can for example be seen in the usage cues of products, like how the user interface of a washing machine communicates to the user what each of its settings means and does.

The effects in the quadrant can be used early on in the design process, to consciously plan the message that a product communicates, and how it wants its user to act, and align this with the design intentions. For a more reflective purpose, they can be used near the end of the design process to study the contents and quality of a product's communications and cues, so that they can be evaluated for their desirability, and thereby also provide information for potential redesigns.

\subsection{To the hand}

In the to-the-hand quadrant, the influences work directly on the user, skipping over the decisionmaking process. These effects need not always be physical to function as described. It looks at the ways that both users' actions and their routines can be restricted or changed. The effects are visible in for example the safety caps that are put on containers of medical and chemical products, or how supermarkets often use the smell of freshly baked goods to entice customers and make them feel comfortable in a subliminal manner that overrules the customer's conscious decision-making process.

The effects in this quadrant can be consciously added early on in a design process, in order to improve for example safety and effectiveness. As a reflective measure, it is viable to look at the direct influences that are present in a designed product, evaluating whether they are desirable and effective, and whether users will be willing to accept them.

\subsection{Behind the back}

The effects in the behind-the-back quadrant are more indirect in the impacts they represent than the other quadrants. These effects relate to the environment surrounding the technologies, and how technologies and the environment influence each other. For example, the introduction of mobile phones has had the side effect that humans now feel a need to always be available and in contact with others, and has moreover lead to a need for strong ICT infrastructure. These effects are difficult to consciously apply when designing a new technology, but should nonetheless be studied to minimize potential negative consequences or product failure.

During development of a new product, knowledge of potential consequences and conditions can be useful to ensure successful and desirable implementation. It can also serve as a reflective means, to look at the societal effects that an existing product has had, and what environmental factors played a role.

\subsection{Above the head}

The above-the-head quadrant focusses less on specific effects, and rather on general views on the role of technology in society. It is mainly meant for ethical reflection and discussion. These reflections can be used in a development process to think about how users may react to the introduction of the product that is being designed. It also forces one to look from a perspective that may differ from one's own, thereby potentially finding out new ideas. For a historical example, the deployment of the atom bomb near the end of World War II can be seen as a sort of turning point, that changed the widespread societal perception of technology from a utopian to a dystopian view.

When designing a new product, it can help to try to look at it from different angles, to more clearly see how it can change society overall in either positive or negative ways. Similarly, it can prove useful to also reflectively subject existing products and technologies to these perspectives, to potentially learn how negative consequences can be avoided in the future, while ensuring that the desirable ones will still be maintained. 


\subsection{Scope of the Tool}

Up until now the PIT has mainly been used as a framework for product designers, with the goal of better products being designed that can lead to a more desirable future (Dorrestijn \& Eggink, 2014). This scope can be extended further, to also be used for more abstract concepts, like innovations, strategies, and corporate identities. Strategic development carries with it a relation with society, much like product design does, with decisions that are made having an impact. The PIT could serve as an aid in this field, providing insight into the different relationships that are present. The strategists will be able to affect society in a more conscious and responsible manner. As such, more effective strategies can be developed that serve more desirable goals.

\subsection{Proposed method}

The PIT can be used as an analytical method in itself, to analyse (future) innovations and policies. Using its model's effects as a sort of checklist, different aspects of a particular subject can be listed and discussed. By analysing the chosen subject based on each of the PIT's twelve effects, one is forced to take a critical stance and to see things from more perspectives (Raub, 2017). The method is meant to be used by for example designers or strategists, in the form of workshops wherein the impact of a new idea is analysed. Diagrams can be used to complement the analysis with visual data (figure 2).

\section{Comparison with existing tools}

To gain insight into how this method relates to the larger field of prospective analysis, it has proven useful to compare it with existing analytical means. Within the field of prospective and strategic development, different tools exist. The choice was made to distinguish two types, namely between corporate- and innovation-oriented perspectives. For each of these perspectives, different tools exist. In the following, a selection of existing tools is discussed and compared for their relation to the PIT and the proposed analytical method. The selection was made based on prevalence within the field and literature (cf. Glaister \& Falshaw, 1999; Johnson, Scholes, \& Whittington, 2008).

\subsection{Corporate-oriented tools}

\subsubsection{SWOT-analysis}

SWOT-analysis serves as a strategic planning tool for businesses and organisations to analyse their position in the market, based on the four areas of Strengths, Weaknesses, Opportunities, and Threats (Osita, Onyebuchi, \& Justina, 2014). SWOT largely focusses on investigating and structuring the results of a particular technology or policy, rather than looking at the particular explanations for those results. This relation to consequences of particular developments shows a kinship with the 'behind-the-back' quadrant of the PIT, specifically with the effect of 'side effects'. The PIT can add more user-interaction and societally related factors to SWOT's mainly economic and market-position focussed features. From this perspective, the right-hand side of the PIT's model (before-the-eye and to-the-hand) looks at factors mainly internally to the company, relating to SWOT's Strengths and Weaknesses, while the left-hand side (above-the-head and behind-the-back) looks at external factors, which in turn show similarities to the Opportunities and Threats of SWOT. The PIT can in this way supplement SWOT's information output.

\subsubsection{Five Forces Model}

The Five Forces Model of Michael Porter uses five dimensions that show the inherent potential for growth and profit in a particular market sector, and that need to be kept in mind by companies in order to successfully defend their position: the threat of potential entrants; the threat of substitute products; the bargaining power of suppliers; the bargaining power of buyers; and the rivalry among existing firms (Porter M. E., 1980, pp. 3-33). Porter's framework concerns itself with fairly abstract, 


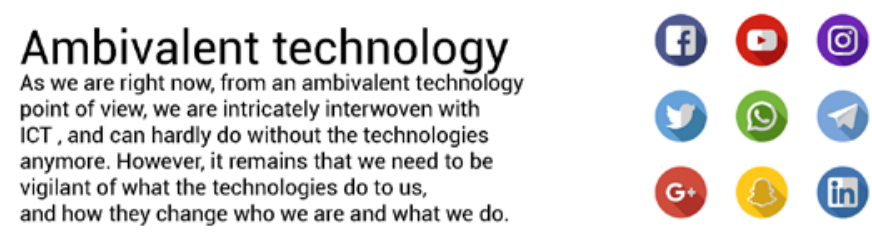

Dystopian technology

From a dystopian viewpoint, ICr companie distract us from ourselves and each other.

ICT products stifle social contact,

and take any and all meaning out of our interactions with other people.

\section{Utopian technology} us with new capabilities and opportunities, thereby unequivocally improving upon our lives and society as a whole.
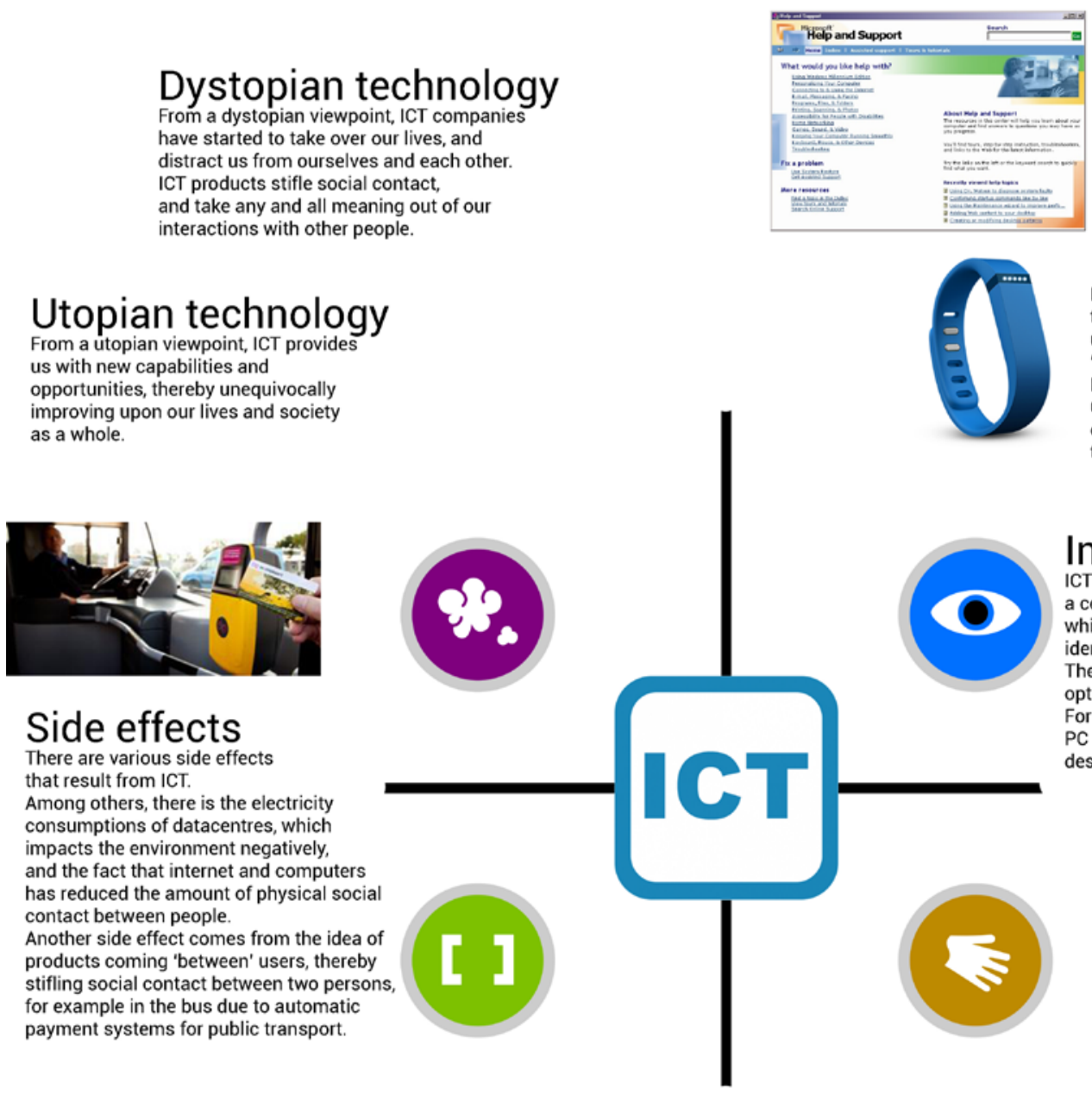

\section{Side effects}

There are various side effects that result from ICT.

Among others, there is the electricity consumptions of datacentres, which impacts the environment negatively. and the fact that internet and computer has reduced the amount of physical socia contact between people.

Another side effect comes from the idea of products coming 'between' users, thereby stifling social contact between two persons, for example in the bus due to automatic payment systems for public transport.

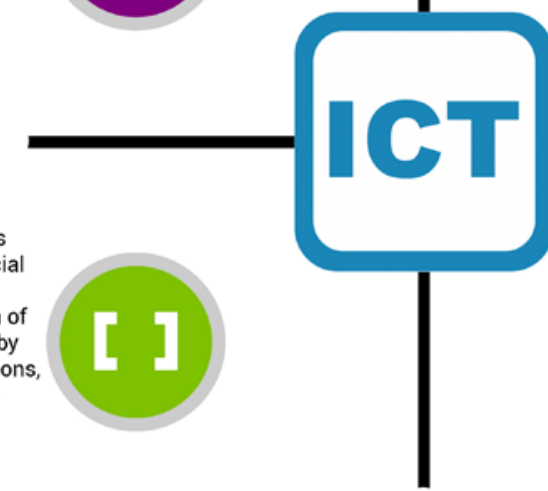

\section{Embodiment}

Especially younger generations have managed to make ICT products part of their routines and embodiment. Think for example of typing or touchscreens. While many companies try to do something similar with older generations, these types of endeavours often meet with problems.

\section{Guidance}

ICT organizations need ways to convey the meaning of functions and purposes to users.

To this end, icons are used

but also textual aides, like help-screens.

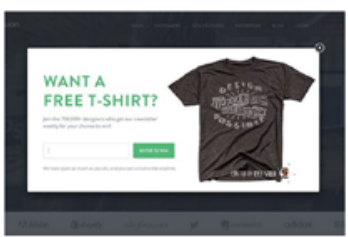

\section{Persuasion}

\section{ICT products have in}

the past been used to encourage users to exhibit for example 'good' or healthy behaviour. For example, Fitbit. On websites, pop-ups and other adverts also work through persuasion of the user.

\section{Image}

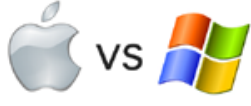

CT products often carry a certain image with them, which the user may use to identify themselves with. There are also sometimes options for customization.

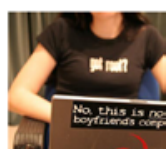
For example, Apple vs. Windows, PC building, but also technologies designed specifically for men or women.

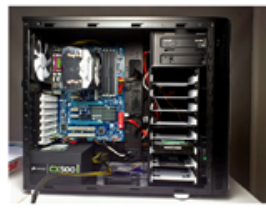

\section{Subliminal affect}

ICT products have been known to make use of subliminal affects in order to get the user to act in a certain manner For example, the use of certain adverts on websites has a subliminal affect.

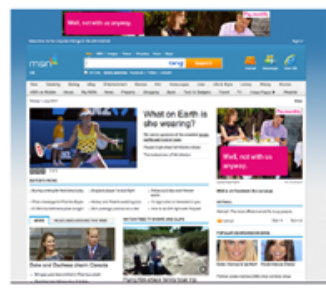

\section{Technical determinism}

There is a certain fear with segments

of the population that ICT has

started controlling our behaviour, and making decisions for us. An example would be modern smart phones, that enable us to always be online and give us to always be andine apps and

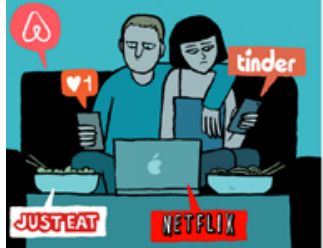
functions, but some people are afraid that these technologies have taken on too big an influence in our lives. It does ring true that ICT has changed our societa values, by creating requirements and demands that did not use to exist before their introduction.

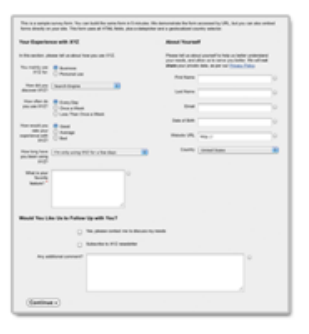

Coercion

Software systems often by their very nature limit the options available to their user, by providing them with a rigid framework to follow during interaction. Think of online forms, for example. A more physical example would be floppy disks, which were later designed to only be able to be inserted in the one correct manner.

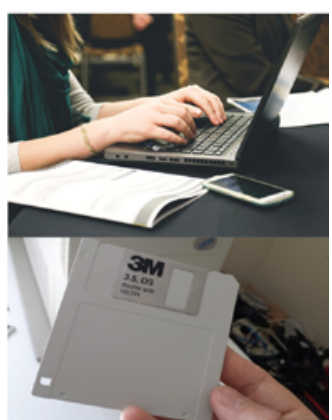

Figure 2 Example diagram of PIT, based on the sector of ICT Companies (Raub, 2017) 
business-focussed concepts, meaning less attention is given to the specific impact that a particular strategy or product can have in society. However, the Five Forces Model does relate to the 'background conditions' effect in 'behind-the-back', as it looks at how external factors influence a proposed project. The two models handle these kinds of themes differently, with Five Forces taking a business-oriented approach, whereas the PIT looks more at societal and technological factors. Usage of both tools therefore can provide strategists and analysts with two important perspectives on which environmental factors may play a role.

\subsubsection{PEST-analysis}

PEST-analysis serves as a framework for analysing environmental market-factors, clustered in Politics, Economics, Social circumstances, and Technological developments, and for each of these factors, separate influences can be listed to provide an image of the industry being worked on (Johnson, Scholes, \& Whittington, 2008, pp. 55-57). Comparison with the PIT shows a certain amount of overlap between PEST's focus on environmental factors and the PIT's 'behind-the-back' quadrant, particularly the effect of 'background conditions'. This can for example be seen in the model of ICT companies (figure 2), where it mentions the technologies' reliance on not only infrastructure but also users' familiarity with technology. Both tools aim to analyse the role of influences in the environment on a product, service, or organisation. The PIT however adds one extra dimension to the discussion, mainly through the 'technical determinism' effect. This effect signifies how society not only influences (technological) developments, but that the reverse also happens, with said developments impacting and changing society. In this way, the PIT adds a new perspective to the conventional PEST-framework.

\subsection{Innovation-oriented tools}

\subsubsection{Technology assessment}

Technology assessment encompasses the practice of analysing the societal impact of new technologies, and is a tool for advising political changes and decisions by anticipating positive and negative consequences of future developments (Porter A. L., 1995, p. 136; Van Est \& Brom, 2012). Both technology assessment and the PIT wish to investigate the potential consequences that may occur as a result of a particular technology being implemented in society. For the latter, this is most apparent in the 'behind-the-back' quadrant's effect of 'side effects'. For both methodologies, awareness of these impacts and consequences is meant to ensure that they are used in societally beneficial ways. The PIT can aid in technology assessment practices by structuring the different factors that play a role, with possible (moral) issues being shown in 'behind-the-back', whereas 'above-the-head' shows potential directions in which a particular technology can take society. The model for ICT companies (figure 2) for example discusses how technologies can come 'between users', stifling interactions. Meanwhile, the 'before-the-eye' and 'to-the-hand' quadrants show the available means to 'steer' a particular innovation in such a way that beneficial effects are ensured and negative ones are avoided as much as possible.

\subsubsection{Scenario planning}

Scenario planning makes use of short narratives to analyse potential future situations that may come as a result of certain decisions and developments, helping analysts to consider and prepare for futures that are not readily apparent and may be overlooked (Schoemaker, 1995; Eggink, Reinders, \& Van der Meulen, 2009). As has already been investigated by Dorrestijn, Van der Voort, and Verbeek (2014), there are certain ways in which scenario planning can be combined with and improved by the PIT. Overlap can mainly be seen in the left side of the PIT's model, in the quadrants 'behind-the-back' and 'above-the-head'. Within the proposed analytical method, the 'above-thehead' quadrant is used to present three scenarios of possible future states surrounding a particular development, as can for example be seen in the model of ICT companies (figure 2). Meanwhile, the findings listed in the 'behind-the-back' quadrant show the environmental factors and impacts that could potentially lead to those futures. In these ways, the PIT can be used to both create and improve scenarios, by raising understanding of the role of potential technologies in society. 


\subsubsection{Technology roadmapping}

A technology roadmap presents a plan or strategy for how a particular new technology or product can be developed and implemented in society, meant to be made in cooperation with as many relevant stakeholders as possible (International Energy Agency (IEA), 2014). The technology roadmapping process starts with an analytical phase, in which the PIT can prove useful. During this phase, different environmental factors that play a role are investigated, showing a relation to the effects in the 'behind-the-back' quadrant, particularly 'background conditions'. By understanding the factors that a particular new concept relies on, and the potential impact that it can have, it becomes easier to determine a desirable means of implementation. Moreover, the 'above-the-head' quadrant, through the potential futures that it presents, can provide information applicable for the 'envisioning' stage of the roadmapping process. Lastly, the PIT could be used as part of workshops with stakeholders.

\subsubsection{Technology forecasting}

Technology forecasting concerns itself with anticipating and understanding future technological changes and innovations, looking also at potential (social) impacts that may come as a result of a particular technology's introduction (Firat, Woon, \& Madnick, 2008). Technology forecasting uses various different tools in its pursuit of predicting future changes and impacts. Most of these take an economic or statistical approach. The PIT could be used to also add a philosophically and ethically oriented perspective that is not yet present. Looking at both desirable and undesirable consequences that may occur as a result of a particular technology's introduction can help when forecasting what possible futures said technology can lead to. The interaction-oriented effects in the 'before-the-eye' and 'to-the-hand' quadrants can help to show how an innovations effects can to an extent be 'steered' so that more desirable results are achieved. In these ways, the PIT can offer a valuable addition for the practice of technology forecasting.

\subsubsection{Technological innovation systems}

The approach of technological innovation systems seeks to analyse technological change by looking at the broader social structures that connect different companies and organisations, and how these institutions impact a particular technology or technological field (Suurs, 2009). Inherent to the technological innovation system is the idea that social structures influence and impact technologies. This shows overlap with the views of the PIT, most noticeably in the 'behind-the-back' quadrant. In this regard, the PIT however also adds the perspective of technology's vice versa influence on society. The PIT and proposed methodology can structure those ideas that are relevant when studying the innovation system of a particular technology, while also adding this aforementioned perspective of the overall interdependency of technology and society.

\subsubsection{Technology acceptance model}

The technology acceptance model provides different factors that play a role in whether a user will want to use a particular product, and how they will use it, mainly focussing on the two factors of 'perceived usefulness' and 'perceived ease of use' (Davis, 1989; Venkatesh \& Davis, 2000). The technology acceptance model's focus on particularly the 'perceived' usefulness and usability can clearly be related to the PIT's 'before-the-eye' and to a somewhat lesser extent 'to-the-hand' quadrants. Study of these specific fields during analysis with the PIT can thus provide useful insights when determining whether a user will be willing to 'accept' a particular new product or technology. Moreover, the scope can be extended to not only look at whether users will accept a particular technology, but also to investigate whether said technology will be accepted by society overall according to its values. In this manner, the PIT can provide additional insights that further analyses using the technology acceptance model can benefit from.

\subsection{Summary of results}

It can be seen that the PIT can serve as a useful addition for the field of future planning and prospective analysis. In the investigations of the different existing methods, no explicitly notable 
difference in potential was found between the two categories of corporate- and innovation-oriented tools. By looking at societal impact and human-technology relations, the PIT adds new perspectives and dimensions to the perspectives by the existing methodologies. Conversely, current methodologies also provided information that could serve as effective input for analyses that use the proposed analytical method of the PIT. In this way, the PIT and existing methods and models can complement and benefit from each other, leading to more useful information being found. It is expected that the knowledge garnered in this manner will in turn prove valuable when planning the implementation of new strategies or innovations, by allowing those responsible to do so in an effective, desirable, and responsible manner.

\section{Case study of future transport}

A case study will be presented to illustrate how the PIT can be used to analyse current and future concepts. Doing so can further demonstrate the added value that the PIT and the proposed methodology can offer to the field. While both corporate- and innovation-oriented subjects showed potential, the choice was made here to focus on an innovation-oriented subject. To this end, the following will first present a concept for future personal transportation, originally developed by the Dutch Study Centre for Technology Trends (STT), which will then be analysed using the PIT. STT serves as an institute that explores potential future concepts and scenarios surrounding innovative technologies, while also posing challenges and risks. Their approach can broadly be described as technology forecasting, to the end of which workshops are used with relevant stakeholders, as well as for example students, combined with desk research and interviews. For illustrative purposes, they also make use of scenarios. For the theme of future personal transportation, STT presents three concepts (Van Voorst tot Voorst \& Hoogerwerf, 2014). While each of these have been analysed (Raub, 2017), the following will only present the analysis of one concept. In their report of the concept, STT themselves also offer an analysis of the potential impact (Van Voorst tot Voorst \& Hoogerwerf, 2014, pp. 19-24), thereby offering a good point of comparison for the results that were found with the PIT.

\subsection{STT's concept: Transportation on Demand}

In the proposed concept, in the year 2040, personal transportation will largely take place using autonomously driving cars. Moreover, people will no longer own their own vehicles, because these cars will be rentable on demand. The concept includes a so-called 'digital journey assistant', which will be used to operate the rental system. The expected form of this 'assistant' is a smartphone app. Shorter distance transport would be taken care of by individual vehicles, which will also be able to transport passengers to 'transport hubs', where the passengers can change over to other forms of travel, like train or plane, for longer distance travel. After transport, the vehicles can find a parking spot and charging station by themselves, where they will wait until they are needed again. The concept envisions that these services will be provided by not only conventional automotive companies, but also by lifestyle brands, like Apple or Walmart (ibid., pp. 19-24).

In the following, this concept will be analysed using the PIT. The analysis was performed by the authors themselves. For each of the PIT's twelve effects, ideas were generated for the potential impact that this concept will have. These ideas will be further explained in the text. A visual diagram was made to summarise the findings (figure 3 ). 


\section{Dystopian technology
The concept of transport on demand will make} The concept of transport on demand will make
humans more isolated, as they are driven around in their personal self-driving cocoons, disconnected from the world outside and from each other.

Especially the elderly will lose all contact with others, as they are constantly alone in their autonomous cars. Brands will take control of people's lives, deciding over when, where, and how they will travel.

The newly added free time will lead to humans losing

their sense of purpose, becoming bored and depressed.

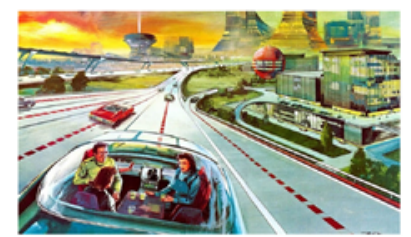

\section{Utopian technology}

to travel more easily, and more often. Both long and short distance travel will be made available for everyone, including those who currently cannot drive a car. Travelling will become more enjoyable, and provide people with more time for leisure, as the burden of driving is taken off of their shoulders.

\section{Side effects}

A first possible side effect of the concept is that certain jobs will become redundant. Further, due to the large variety of service providers, not all systems will connect perfectly, meaning users will still have to experience wait times between transport. There are also risks involved with putting citizens who are unfit to drive in a position where they may can or have to intervene with the cars' actions, leading to potential accidents. There is also the question of what people will do with their newly gained free time, as boredom can potentially lead them towards undesirable behaviour or depression.

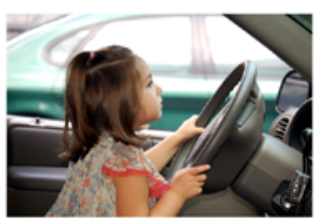

\section{Ambivalent technology} ansport on demand may sound very convenient, but it also comes with certain risks and caveats. It should be made sure that people, especially elderly, are not always travelling alone, and rathe using their new free time in the car to connect with the people and the world outside.

The cars themselves should be designed in such a way as to allow passengers to spend their new free time in a valuable and worthwhile way.
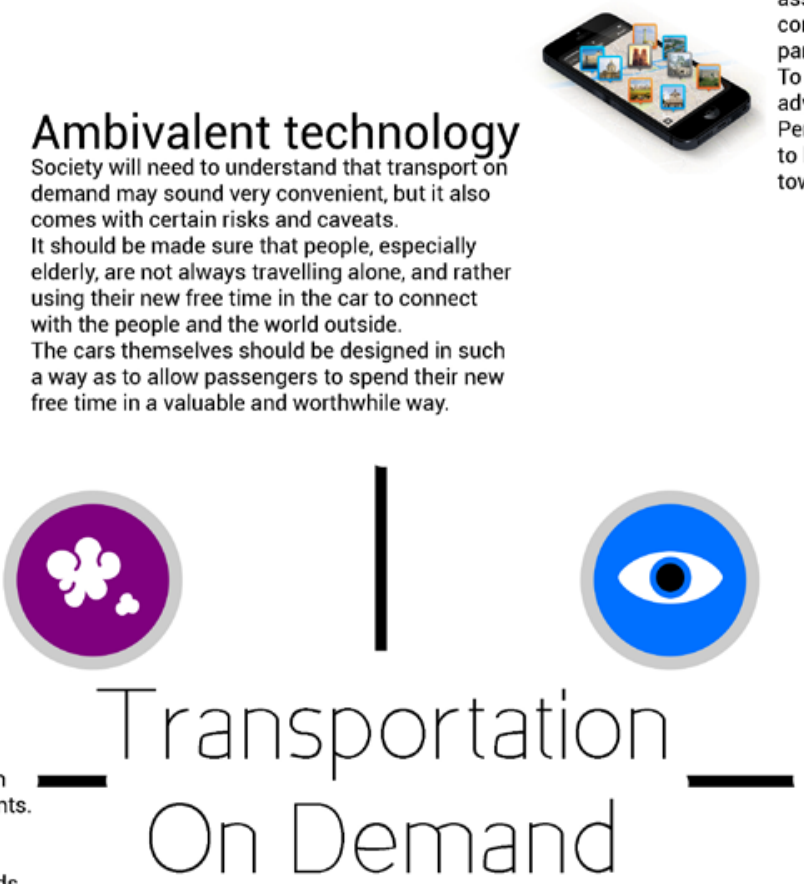

\section{Persuasion}

The service providers and owners of the different 'digital journey assistant' apps will want to persuade consumers towards using their particular products and services. To this end, they can make use of To this end, they can make adverts and special offers. to lead users around the vehicles towards correct and safe behaviour.

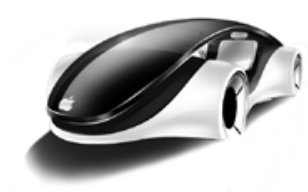

\section{Image}

The new autonomous cars will be provided by different lifestyle brands. Each seperate brand will bring with it a particular kind of image.

The choice in different brands can allow users to choose the image that best fits them, in regards to both their needs, but also their lifestyle.

\section{Background conditions \\ The proposed concept will require new laws and} regulations, to allow the cars on the public roads. Regulations are also needed regarding insurance. Both users and other stakeholders in the traffic system would need to accept the new vehicles. Travellers will need to trust the service providers, as well as the providers trusting each other, for example when it comes to exchanging of data. There will also be a need for a reliable and robust ICT infrastructure to let the cars function.

\section{Technical determinism} As people will no longer own their own personal vehicles, they will become dependent on the cars and the service providers for transport.

The value of independence may become less important, as becomes normalized for people to be driven to their destinations by the technologies. It may also change what it means to be old, as the concept aims to allow among others the elderly to be able to travel more and more easily, thereby removing the stigma of them being immobile and also isolated from the outside world.
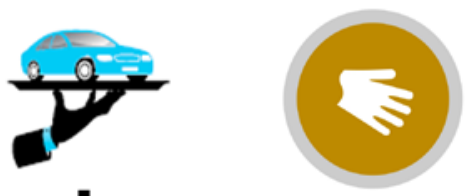

\section{Coercion}

Once in the car, the vehicle will start driving on its own, following a pre-planned route, which allows little freedom of choice for users. While it is moving, the passenger is confined in the car's interior waiting until they reach their goal. In these ways, the proposed concept limits the user's options and actions.
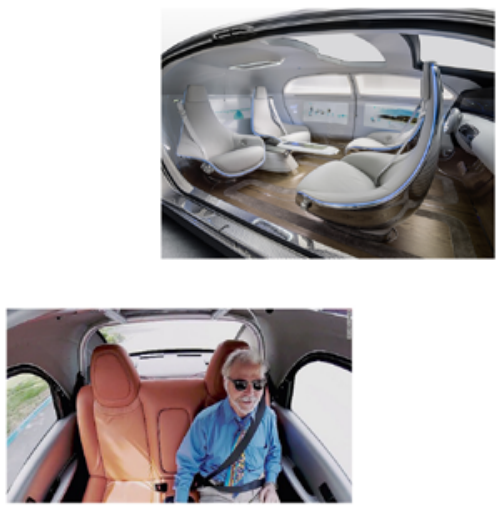

\section{Embodiment}

The process of ordering a vehicle, sitting down in it, and then being brought to one's desination is meant to merge with its user's daily routines To do this, the service will need to be easily accessible, so that the activity After this, the user will more instinctively choose to use the services, whenever they need to travel somewhere.

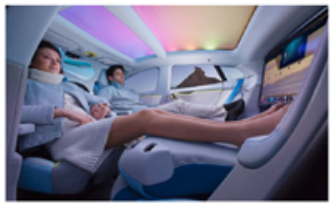
casily accessible, so that the activity

\section{Subliminal affect}

To encourage people to use the new services, companies will want to use subliminal affect. With this in mind, the cars themselves should be as comfortable and convenient as possible. By allowing for comfortable travel, and letting them do other things while in the car, like letting children play in a special area, the experience will be seen as more positive by the passengers. In doing so, they will be subconsciously affected to use the services again in the future. 


\subsection{Before the eye}

The proposed implementation of rentable autonomous vehicles will need to convey information to its users and customers. Clear and neutral information will need to be given, but the service providers will most likely also want to apply persuasion. The concept specifically brings forward branding, so the effect of image will also play a part.

\subsubsection{Guidance}

Guidance in this concept will first come as part of the 'digital journey assistant', that provides users with information about the transport they requested. The app needs to clearly communicate how the users will reach their intended destinations. The concept does not go into detail about information that the vehicles themselves will provide, but guidance will be needed here too. This can be in the form of for example displays that indicate how far the user is from their destination, or sound cues. Another aspect that is missing is the information for other people around the car, like pedestrians and cyclists. These actors will require information about what the vehicle is doing or about to do, in order to increase safety, which could be communicated using for example lights or sound.

\subsubsection{Persuasion}

The service providers will want to persuade users towards using their particular cars. Though the concept does not go into detail about this, an idea about how this could be done is through marketing. Using adverts or special offers, vehicle providers can encourage users to choose their particular services. Similarly, the providers of the different 'digital journey assistant' apps will need to use such measures to convince consumers to choose their particular offerings. Another question about the concept is how it can lead people around the car, like pedestrians, towards correct and safe behaviour.

\subsubsection{Image}

According to the concept, different lifestyle brands will try to get a stake in the self-driving vehicle market. These different brands will each offer a certain image. The Apple-brand car would be considered modern and functional, whereas the Walmart-branded one is seen as convenient and affordable, to name a few examples. The technology and its experience are in this concept meant to be somewhat customisable. Users will be allowed to create a driving experience that fits not only their particular needs, but also their personal image and lifestyle. The overall image of the proposed self-driving vehicle system will most likely be one of convenience and ease. There will also, at least at first, likely be an image of luxury, as the act of being driven around reminds one of the image of having a personal chauffeur.

\subsection{To the hand}

This concept will interact with users in a direct manner as well. Coercive elements will be in place that limit the users' options. The technology is meant to merge seamlessly with people's activities. The self-driving cars will also have certain aspects of subliminal affect, that lead users to repeat usage of the services in the future.

\subsubsection{Coercion}

After a user sits down in the car they requested, the vehicle will start driving on its own. It will follow a pre-planned route, leaving the passenger with little freedom of choice. Moreover, while the vehicle is moving, the user will be confined inside, needing to wait until they reach their destination or the car is stopped. This last point is especially relevant, since discussions by both STT and others often focus on the idea that passengers will be able to do other things while travelling, whereas the fact that they will still be confined to the car's interior is often forgotten. These two aspects represent ways in which freedom of action is taken from users through the proposed introduction of autonomous vehicles. 


\subsubsection{Embodiment}

The practice of ordering a self-driving vehicle, entering it, and then being driven to one's destination is meant to merge seamlessly with and become embedded in people's natural routines. To this end, the service will need to be easily accessible, so that it can become, after the first few uses, natural to the user to order a car this way. After it is embodied in this way, the user will no longer need to put active thought and effort into the ordering- and travelling-processes.

\subsubsection{Subliminal affect}

In order to encourage people to make use of self-driving vehicles, the service providers will want to make use of subliminal affect. A main factor in this is to make the autonomous cars and the transport they offer as convenient and comfortable as possible. By allowing customers to travel comfortably, and enabling them to do other enjoyable things during travel, users will associate the experience with positive feelings. Thereby they are subconsciously influenced to more likely use the services again in the future.

\subsection{Behind the back}

The concept will need to keep certain environmental aspects and factors in mind for it to be successfully implemented. Certain side effects may came as a result. The vehicles will also rely on certain conditions to function. Lastly, there is the potential for this technology to steer society, and change the values that are held.

\subsubsection{Side effects}

One potential consequence of the proposed concept is that certain jobs will become redundant, like taxi and bus drivers. However, the act of travelling will be made more accessible and easier, potentially improving humans' cultural and social development. A related advantage of the system that STT themselves mention is the added independence for for example older citizens or people with no driver's license, as they will now be able to travel more easily (Van Voorst tot Voorst \& Hoogerwerf, 2014, p. 23). This may however also first lead to a reduction in social contact for these people, as they will no longer be driven around by friends and family, but second also brings forth the issue of putting people unfit for driving into a situation where they may still need to take on a supervisory role over the system. Another benefit that is listed by STT is the added free time for work or leisure, due to passengers no longer needing to drive themselves. It is unknown however what people will use this newfound free time for. While the intention is to raise productivity and happiness by allowing people to either work or relax during travel, there is the risk that passengers will start to experience severe boredom and lack of purpose. This in turn can potentially lead to undesirable actions like vandalism of the vehicles, or even lead to mental health problems like depression.

\subsubsection{Background conditions}

The concept itself lists certain 'preconditions' that need to be met to successfully implement the proposed system (ibid., pp. 20-21). First, new road laws will be needed to allow the vehicles to drive on the public road. There is also a need for new insurance regulations, so that the right actors can be held responsible in case of accidents. Second, autonomous vehicles will need to be accepted by both the users themselves, as well as other stakeholders in the transport system. Third, travellers will need to put their trust in the service providers, as well as the service providers trusting each other. For STT, this is specifically about the sharing of information and data, but in reality this need for trust will also concern subjects like safety. Besides these conditions, there is also for example a need for a strong ICT infrastructure, that can reliably handle the massive data exchanges that are needed to allow the self-driving vehicles to function.

\subsubsection{Technical determinism}

The introduction of 'transportation on demand' has the potential to bring certain changes to society and its values. First, people will become dependent on the system for their travelling, as they will no longer be owning their own cars. The value that is held for human independence may thereby also 
be lessened, as it becomes normalised for people to be driven to their destination by technological systems. In addition, if STT's intentions are fulfilled, the meaning of for example old age may be changed, as elderly citizens become once more able to travel easily, removing the stigma of them being immobile and isolated.

\subsection{Above the head}

There are different perspectives through which one may look at the social impacts of this concept. One can look at it fairly optimistically, seeing the potential benefits it can bring to improve our human capabilities. Or one can see its dystopian side, focussing on its possibly undesirable side effects. A third perspective would aim to look at the concept in an ambivalent manner, seeing both the risks and benefits, and to understand how it could be implemented in the most desirable way.

\subsubsection{Utopian technology}

From a utopian perspective, 'transport on demand' will lead to people being able to travel more easily and more often than they are currently able. Both long and short distance travel will be made available for everyone, even those that currently cannot drive a car. The act of travelling will be made more enjoyable, as passengers can spend their time on leisure. With the burden of driving taken off the shoulders of passengers, they get extra free time, which they can use to work towards fulfilling their true potential as humans undistracted.

\subsubsection{Dystopian technology}

From a dystopian perspective, this concept will lead to humans becoming isolated in their personal self-driving cocoons, disconnected from the outer world and the people around them. Elderly citizens will lose the contact they had with others, as they are constantly alone while being driven around by autonomous vehicles. People's lives will become even more controlled by brands, as companies come to decide over when and how they travel. The free time that is supposedly added will only lead to people losing their sense of purpose, becoming bored and depressed.

\subsubsection{Ambivalent technology}

From an ambivalent perspective, society will need to understand that, convenient as 'transport on demand' may sound, it comes with certain risks and caveats. It needs to be ensured that people, especially the elderly, are not made to always be travelling alone in their autonomous vehicles, but rather use their newfound free time in the cars to connect with others. The cars themselves will also need to be designed to allow passengers to spend their travel time in a valuable and worthwhile manner that stimulates them.

\section{Discussion}

Analysis of the concept proposed by STT using the PIT showed that there is an added value in using it as a supplementary means of study. By ordering insight inspired by the PIT's twelve effects into the model, it became clear that certain aspects had been neglected by STT's conventional technology forecasting approach. Through use of the PIT, this missing information was found, and thus can be taken into consideration when planning the concerning technology's introduction into society.

The quadrants on the right side of the PIT's model (before-the-eye and to-the-hand) were largely used to theorize about how the proposed systems could function in detail, and other aspects that needed to be kept in mind with regard to usability and functionality. In doing so, details were added that were still missing from STT's own analyses.

The assessment of the concept by STT themselves could be considered fairly optimistic, if not utopian. Important negative consequences of the proposed plans had either not been found in the approach used by STT, or went unmentioned due to other reasons. That said, there were also certain positive effects and consequences of the concept that were not mentioned by STT, but were found out during analysis with the PIT. For example the increased accessibility and ease of travelling, which can potentially improve cultural development. These types of aspects were mainly 
investigated through the quadrants on the left side of the PIT's model (behind-the-back and abovethe-head).

Overall it became clear during the analysis that the added value of the proposed analytical method of using the PIT lies in providing new insights and perspectives. This is achieved by making the analysts look critically and from multiple sides on the subject they are working on. This also provides them with a more ethically oriented approach. The proposed method serves as an additional measure, that should be used in combination with the tools and methods that already exist. During the case study, it also became clear that this kind of intricate analysis of potential impacts can change one's perspective and opinion on the desirability and feasibility of a particular concept. By using this proposed method, strategists are provided with more information about the potential role and impact of their subject in society, aiding them in both studying its desirability and in determining the most effective and responsible manner of implementation.

\section{Limitations and future work}

Certain limitations and questions still remain within the research demonstrated in this paper. First, the present research did not include a critical assessment of whether the PIT includes all the necessary and relevant themes and aspects. The PIT may still require further refining and development. Improvements in the PIT will lead to the developed method functioning more effectively. Second, the research could benefit from the undertaking of a case study of a corporateoriented subject, as the ones that have been done already are innovation-focussed. Third, the case study was performed by the authors themselves. The method has not yet been tested with experts in the field of strategic development and analysis. Doing so would garner more information about the added value of the method in actual practice.

\section{Conclusions}

This paper aimed to demonstrate the potential for using the PIT as an analytical instrument for prospective thinking about future strategies and innovations. The PIT's twelve effects were investigated, an application method has been proposed, and its position in relation to existing methods in the field has been examined. The method has furthermore been applied in a case study, to demonstrate its potential. In doing so, it was shown that usage of the PIT in this manner can provide analysts and strategists with new and relevant information. The method is explicitly meant to be used in combination with ones that already exist. Because of the reflective and human-centred nature of the PIT, analysts are aided in making decisions in the development of new technologies, so that these will have a more effective, desirable, and responsible impact in society.

\section{References}

Davis, F. D. (1989). Perceived Usefulness, Perceived Ease of Use, and User Acceptance of Information Technology. MIS Quarterly, Vol. 13, No. 3, 319-340.

Dorrestijn, S. (2012) The design of our own lives: Technical mediation and subjectivation after Foucault. Enschede: University of Twente

Dorrestijn, S., \& Eggink, W. (2014). Product Impact Tool Workshop - Mastering Affect and Effect in HumanProduct Relations. Proceedings of the Colors of Care: The 9th International Conference on Design \& Emotion (pp. 467-469). Bogota: Ediciones Uniandes.

Dorrestijn, S., van der Voort, M., \& Verbeek, P.-P. (2014). Future user-product arrangements: Combining product impact and scenarios in design for multi age success. Technological Forecasting \& Social Change, 89, 284-292.

Dorrestijn, S. (2016, May 31). Product Impact Tool. Retrieved from stevendorrestijn.nl: http://stevendorrestijn.nl/tool/

Dorrestijn, S. (2017) "The Product Impact Tool: And the Case of the Dutch Public Transport Chip Card". In: Niedderer, Clune, Ludden (eds.). Design for Behaviour Change (Ashgate Design for social responsibility series) (ch. 4). Farnham: Gower 
Eggink, W., Reinders, A.H.M.E., \& Van der Meulen, B.J.R. (2009) “A practical approach to product design for future worlds using scenario-development". In: Clarke, A, McMahon, C, Ion, W and Hogarth, P (Eds.). Creating a Better World - Proceedings of the 11th International conference on Engineering and Product Design Education. Brighton: The Design Society.

Firat, A. K., Woon, W. L., \& Madnick, S. (2008). Technological Forecasting - A Review. Cambridge: Massachusetts Institute of Technology.

Glaister, K. W., \& Falshaw, J. (1999). Strategic Planning: Still Going Strong? Long Range Planning, Vol. 32, No. 1, 107-116.

IEA. (2014). Energy Technology Roadmaps: a guide to development and implementation. Paris: IEA.

Johnson, G., Scholes, K., \& Whittington, R. (2008). Exploring Corporate Strategy. Harlow, Essex: Pearson Education Limited.

Osita, I. C., Onyebuchi, I., \& Justina, N. (2014). Organization's stability and productivity: the role of SWOT analysis an acronym for strength, weakness, opportunities and threat. International Journal of Innovative and Applied Research, vol. 2, Issue (9), 23-32.

Porter, A. L. (1995). Technology Assessment. Impact Assessment 13:2, 135-151.

Porter, M. E. (1980). Competitive strategy: techniques for analyzing industries and competitors. New York: Free Press.

Raub, T. (2017). Using the Product Impact Tool for Future Planning. Enschede: University of Twente

Schoemaker, P. J. (1995). Scenario Planning: A Tool for Strategic Thinking. MIT Sloan Management Review, Winter, 25-40.

Suurs, R. A. (2009). Motors of Sustainable Innovation - Towards a theory on the dynamics of technological innovation system. Utrecht: Universiteit Utrecht.

Van Est, R., \& Brom, F. (2012). Technology Assessment, Analytic and Democratic Practice. Encyclopedia of Applied Ethics, Second Edition, vol. 4, 306-320.

Van Voorst tot Voorst, M.-P., \& Hoogerwerf, R. (2014). Tommorow's Transport Starts Today. The Hague, Netherlands: Stichting Toekomstbeeld der Techniek.

Venkatesh, V., \& Davis, F. D. (2000). A Theoretical Extension of the Technology Acceptance Model: Four Longitudinal Field Studies. Management Science, Vol. 46, No. 2, 186-204.

About the Authors:

Thomas Raub is a master student of Industrial Design Engineering at the University of Twente, in the track of Human Technology Relations. His interests lie in the role of technology in society, and how users' attachment to their products can be raised.

Steven Dorrestijn is a philosopher of technology and senior lecturer/researcher in ethics and technology at Saxion University of Applied Sciences, and developer of the Product Impact Tool. In his research Dorrestijn focuses on people's practices when accommodating new technologies in their lives.

Wouter Eggink is a design professional and assistant professor at the University of Twente in the faculty of Engineering Technology. He is especially interested in the relationships between design, technology, and society, and is coordinator of the master programme Human Technology Relations. 